\title{
Glucagonoma syndrome: a case report with focus on skin disorders
}

This article was published in the following Dove Press journal:

OncoTargets and Therapy

14 August 2014

Number of times this article has been viewed

\section{Sheng Fang \\ Shuang Li \\ Tao Cai}

Department of Dermatology, The First Affiliated Hospital of Chongqing Medical University, Chongqing,

People's Republic of China
Correspondence: Tao Cai

Department of Dermatology, The First Affiliated Hospital of Chongqing Medical University, I Youyi Road, Chongqing, 4000 16, People's Republic of China Email caitaocypf@।63.com

\begin{abstract}
Glucagonoma syndrome is a rare paraneoplastic phenomenon. Necrolytic migratory erythema is often one of the first presenting symptoms. We report a case of a 55-year-old man with a 2-year history of recalcitrant eruption. Abdominal computer tomography was performed, which revealed a tumor in the tail of the pancreas. After pancreatectomy, his cutaneous lesions vanished in a few days. Skin symptoms are important, as they are often essential for early diagnosis of glucagonoma syndrome and may prevent metastatic disease; hence, in this report, we focus on skin disorders in glucagonoma syndrome.
\end{abstract}

Keyword: necrolytic migratory erythema

\section{Introduction}

Glucagonoma syndrome is a rare paraneoplastic phenomenon defined as necrolytic migratory erythema (NME), glucagonoma, glucose intolerance, anemia, weight loss, glossitis, and cheilitis. ${ }^{1}$ Because of its rarity, the correct diagnosis is often made too late, leading to poor prognosis. However, NME presents as a hallmark clinical sign of glucagonoma syndrome. ${ }^{2}$ Its early recognition allows for early diagnosis of the tumor and leads to a better prognosis.

Herein, we describe a man admitted to the dermatology ward of The First Affiliated Hospital of Chongqing Medical University with NME, which was later found to be associated with glucagonoma. To our knowledge, there have been few reports of NME from the People's Republic of China. This case demonstrates that glucagonoma syndrome can occur in those of Chinese ancestry.

\section{Case report}

A 55-year-old man was referred to our department with a persistent cutaneous eruption that had been present for 2 years. He was diagnosed with eczema. The patient was asked for his medication history, which revealed that he had been prescribed systemic treatment of oral prednisone acetate tablets (Zhejiang Xianju Pharmaceutical Co., Ltd., People's Republic of China) at the dose of $10 \mathrm{mg}$ three times a day $(30 \mathrm{mg} / \mathrm{d})$ for the last 2 months and Clarityne tablets (Shanghai Schering-Plough Pharmaceutical Co., Ltd., Shanghai, People's Republic of China) at the dose of $10 \mathrm{mg}$ once daily $(10 \mathrm{mg} / \mathrm{d})$ for the 3 months. Additionally, he was being treated with Eloson cream for external use (Shanghai Schering-Plough Pharmaceutica). Although the patient's adherence was good, there had been no obvious improvement of the skin disorder. During the therapy, renal and hepatic organ function data were normal. The skin eruption had started at his lower 

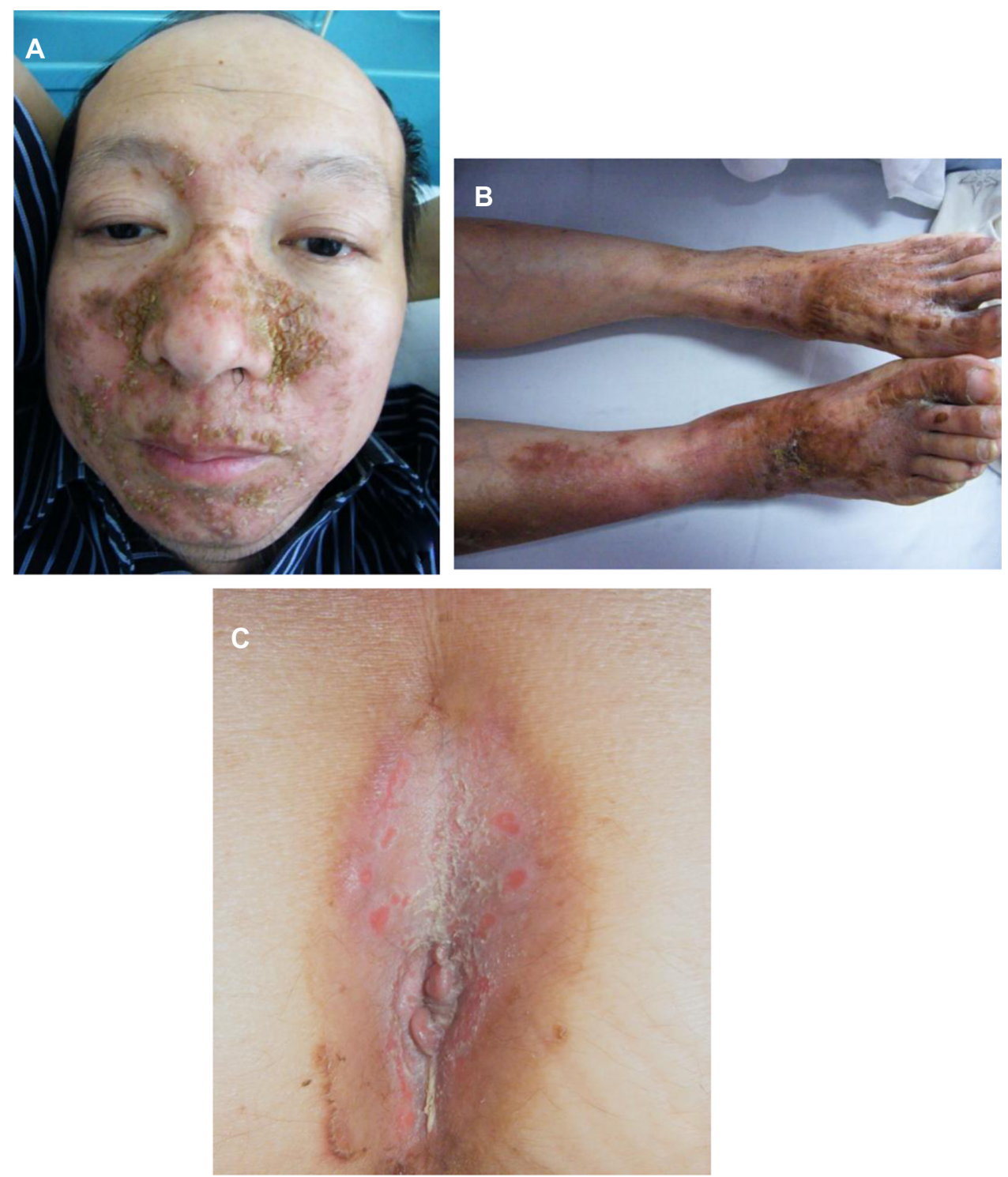

Figure I Necrolytic migratory erythema with erosion and crust formation. Notes: (A) Face; (B) legs; (C) perianal region.

extremities but had rapidly involved his upper extremities, face, and perianal region (Figure 1). Lesions had presented, with advancing borders, erosion, and crusting, resulting in a scalded appearance. The entire course had developed in episodes. The patient also complained of weight loss (almost 7 $\mathrm{kg}$ in 1 year). His longstanding diabetes mellitus had worsened and he started insulin therapy. The family history was negative for multiple endocrine neoplasia or diabetes mellitus. Routine and immunological laboratory findings were unremarkable, except for mild anemia (hemoglobin $80 \mathrm{~g} / \mathrm{L}$ ) and a random glucose concentration of $15.1 \mathrm{mmol} / \mathrm{L}$. Serum zinc level was normal. His levels of serum iron, vitamin B12, and erythropoietin, as well as the number of reticulocytes, were found to be normal. Skin biopsy revealed psoriasiform acanthosis, parakeratosis, and spongiotic epidermis, showing a large zone of necrolysis in the upper epidermis (Figure 2). Abdominal computed tomography scan revealed a hypervascularized tumor measuring 5-7 $\mathrm{cm}$ in the tail of his pancreas and an absence of liver metastasis (Figure 3). His level of serum glucagon was elevated to $1,625 \mathrm{pg} / \mathrm{mL}$. The patient underwent surgical distal pancreatectomy with total tumor excision, and the cutaneous lesions vanished 1 week after surgery (Figure 4). Our patient has been without recurrence for 1.5 years since the surgery and remains asymptomatic.

\section{Discussion}

In 1942, Becker et al described a patient with a typical skin disorder with pancreatic neoplasm. ${ }^{3}$ More than 20 years 


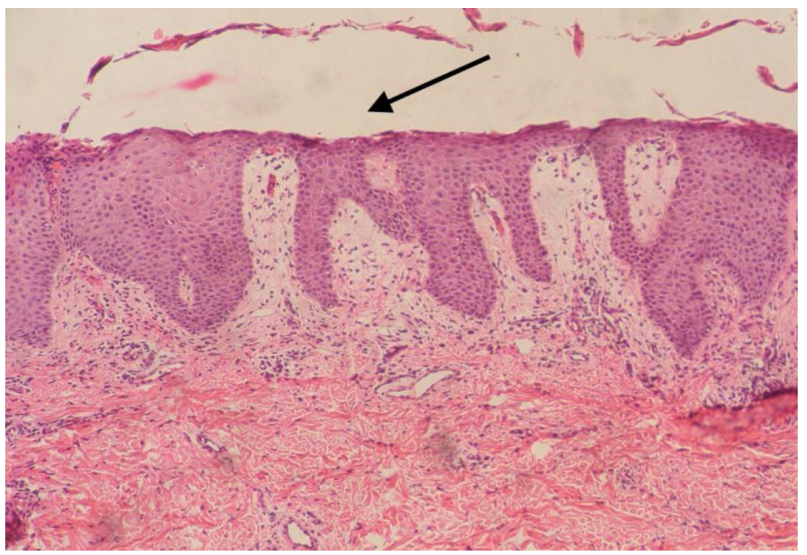

Figure 2 Skin biopsy in necrolytic migratory erythema showing a large zone of necrolysis in the upper epidermis (arrow).

Notes: Hematoxylin and eosin staining; magnification $\times 40$.

later, McGavran et al reported glucagonoma syndrome in association with cutaneous eruptions. ${ }^{4}$ Systemic manifestations of the syndrome include diabetes, anemia, thrombosis, NME, weight loss, glossitis, cheilitis, diarrhea, and psychiatric disorders. Our patient suffered from diabetes, weight loss, anemia, and typical cutaneous eruptions. However, there are also examples of pseudoglucagonoma syndrome, in which NME occurs in malignancies (other than pancreatic), celiac disease, chronic pancreatitis, hepatic cirrhosis, and nutritional deficiencies. ${ }^{5}$

There are many theories to explain the pathogenesis of NME; however, the exact causes are still unknown. The role of glucagon in the causation of NME is supported by evidence. ${ }^{6,7}$ Patients often experience remission of the rash after therapy with somatostatin analogs. ${ }^{6}$ Also, if glucagonomas are surgically removed, as with our patient, then the skin

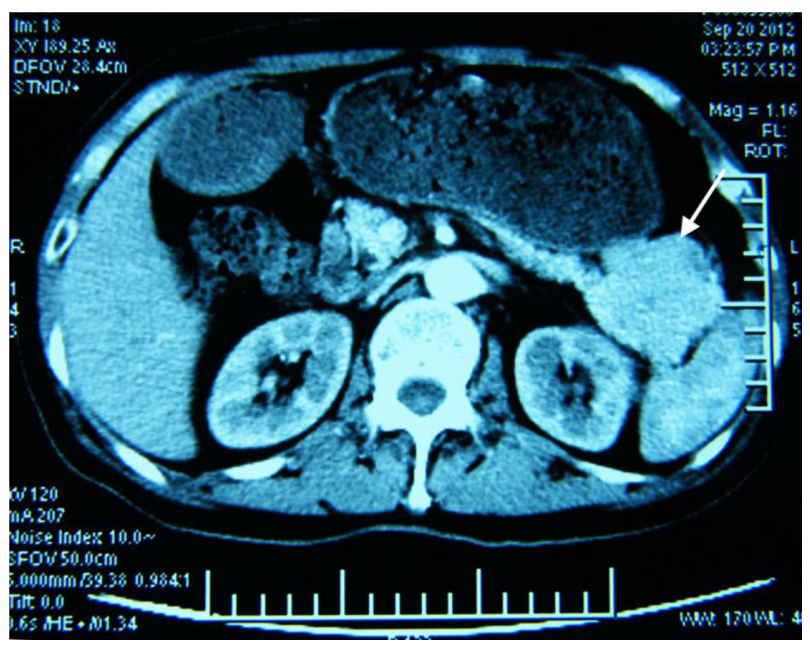

Figure 3 Computed tomography scan of the abdomen of the patient showing a large tumor in the tail of the pancreas. lesions of NME will obviously resolve. Alternative theories to explain the pathogenesis of NME may relate to glucagon. For example, hyperglucagonemia provokes multiple nutrient and vitamin B deficiencies, which, in turn, are the probable cause of this typical skin presentations of glucagonoma syndrome. By immunofluorescence and immunohistochemistry, a large amount of glucagon can be found in the epidermis, without immunoglobulin or $\mathrm{C} 3$ complement, suggesting that excessive glucagon sedimentation causes abnormal cell metabolism and damage. High levels of glucagon may also induce epidermal inflammatory substances, such as arachidonic acid, which may cause skin injury. ${ }^{8}$

Manifestation of NME occurs in $70 \%$ of patients with glucagonoma syndrome. ${ }^{9}$ NME may be the only manifestation at the beginning of the disease. It commonly affects the perineum and other intertriginous sites. The trunk, legs, perioral skin, and sites of minor trauma can also be involved. In our patient, we could see typical lesions that began at the lower extremities and progressed to the face and perianal areas. The lesion is characterized by red patches with irregular borders, intact or ruptured vesicles, and crust formation, so it can be crusty or scaly. ${ }^{10}$ The NME may be just a local erythema, slightly elevated, before its center gradually becomes pale and blisters. When blisters rupture, often the wound and surrounding erythema are covered with scale. The erythema may further expand, and lesions extend outward when the center begins to heal and scar. After exfoliation of scale, the skin is generally smooth and thin, with brown pigmentation. The most specific feature on skin biopsy examination is necrolysis of the upper epidermis. However, histological examination often shows only nonspecific, possibly subacute, dermatitis. Sometimes, histopathology reveals mild perivascular lymphocytic and histiocytic infiltration.

The differential diagnosis for NME includes acrodermatitis enteropathica, pellagra, psoriasis, seborrheic dermatitis, eczema, and pemphigus. Usually, the correct diagnosis is delayed. Since prompt diagnosis and treatment may preclude metastasis of the tumor and lead to a better prognosis, it is important to keep the diagnosis of glucagonoma syndrome in mind.

As glucagonomas are malignant, treatment should be undertaken as soon as possible after diagnosis. An effective treatment strategy should decrease the serum glucagon levels. Surgical removal of the tumor is the generally accepted treatment because of the weak response to chemotherapy. Before operation, efforts should be made to control glucose levels, improve skin rash, give nutritional support, and prevent vein thrombosis. If tumor metastasis has occurred, long-acting 

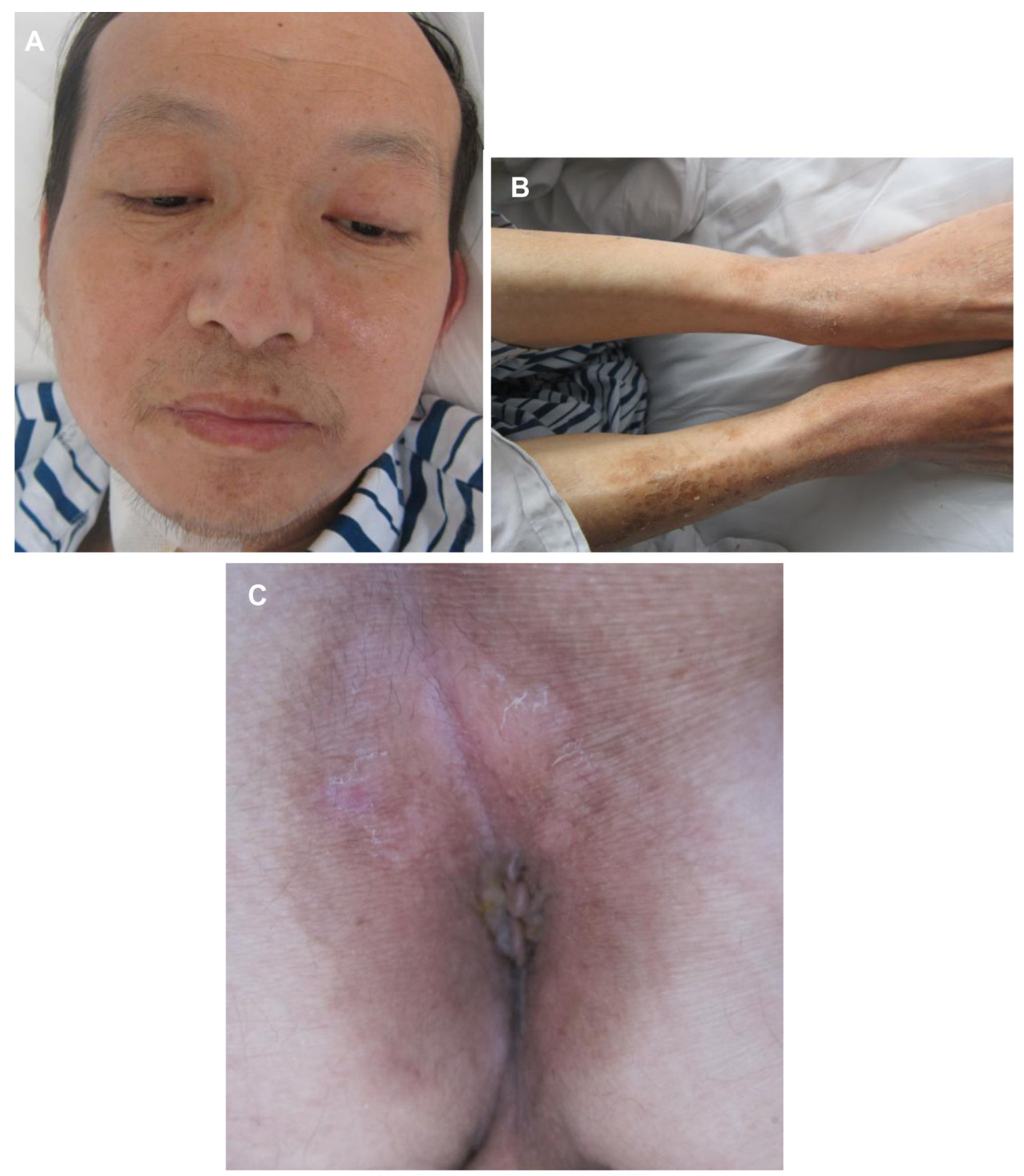

Figure 4 Resolution of cutaneous lesions I week after surgery.

Notes: (A) Face; (B) legs; (C) perianal region.

somatostatin analogs and interferon alpha may be helpful; supplementation with zinc, amino acids, and essential fatty acids appears to be beneficial in some cases. ${ }^{11,12}$

In summary, we have reported a rare case of glucagonoma syndrome, and skin disorders were the main clinical manifestations for which the patient presented to a doctor. After prompt diagnosis and surgical treatment, the cutaneous lesions vanished. When comparing our results to review other cases in the literature, clinical presentation of our patient was typical. Our patient also presented with weight loss, diabetes, a high level of serum glucagon, pancreatic tumor, and NME. However, our patient did not show all the typical manifestations. First, there was no cheilitis or stomatitis, diarrhea, or thromboembolism in our patient. Further, the location of skin lesion was uncommon, as NME in our patient affected the perianal area.

This study is limited by population size. More patients need to be studied to further assess exhibiting characteristics and appropriate treatment.

From a dermatological perspective, we aimed to emphasize the importance of NME in glucagonoma syndrome. Clinicians must have sufficient knowledge to be able to recognize and manage this rare malignant condition.

\section{Acknowledgment}

Written informed consent was obtained from the patient for publication of this case report and accompanying images. 


\section{Disclosure}

The authors report no conflicts of interest in this work.

\section{References}

1. Mallinson CN, Bloom SR, Warin AP, Salmon PR, Cox B. A glucagonoma syndrome. Lancet. 1974;2(7871):1-5.

2. Johnson SM, Smoller BR, Lamps LW, Horn TD. Necrolytic migratory erythema as the only presenting sign of a glucagonoma. J Am Acad Dermatol. 2003;49(2):325-328.

3. Becker SW, Kahn D, Rothman S. Cutaneous manifestations of internal malignant tumors. Arch Dermatol Syphilol. 1942;45:1069-1080.

4. McGavran M, Unger RH, Recant L, Polk HC, Kilo C, Levin ME. A glucagon secreting alpha-cell carcinoma of the pancreas. $N$ Engl $J$ Med. 1966;274:1408-1413.

5. Mullans E, Cohen R. Iatrogenic NME: a case report and review of nonglucagonoma-associated NME. J Am Acad Dermatol. 1998;38: 866-873.

6. Oberkirchner U, Linder KE, Zadrozny L, Olivry T. Successful treatment of canine necrolytic migratory erythema (superficial necrolytic dermatitis) due to metastatic glucagonoma with octreotide. Vet Dermatol. 2010;21(5):510-516.
7. Tierney EP, Badger J. Etiology and pathogenesis of necrolytic migratory erythema: review of the literature. MedGenMed. 2004;6(3):4.

8. Peterson LL, Shaw JC, Acott KM, Mueggler PA, Parker F. Glucagonoma syndrome: in vitro evidence that glucagon increases epidermal arachidonic acid. J Am Acad Dermatol.1984;11(3):468-473.

9. Wermers RA, Fatourechi V, Wynne AG, et al. The glucagonoma syndrome. Clinical and pathologic features in 21 patients. Medicine. 1996;75:53-63.

10. Adam DN, Cohen PD, Ghazarian D. Necrolytic migratory erythema: case report and clinical review. J Cutan Med Surg. 2003;7:333-338.

11. Alexander EK, Robinson M, Staniec M, Dluhy RG. Peripheral amino acid and fatty acid infusion for the treatment of necrolytic migratory erythema in the glucagonoma syndrome. Clin Endocrinol (Oxf). 2002;57:827-831.

12. Hivnor CM, Yan AC, Junkins-Hopkins JM, Honig PJ. Necrolytic acral erythema: response to combination therapy with interferon and ribavirin J Am Acad Dermatol. 2004;50(Suppl 5):S121-S124.

\section{Publish your work in this journal}

OncoTargets and Therapy is an international, peer-reviewed, open access journal focusing on the pathological basis of all cancers, potential targets for therapy and treatment protocols employed to improve the management of cancer patients. The journal also focuses on the impact of management programs and new therapeutic agents and protocols on

\section{Dovepress}

patient perspectives such as quality of life, adherence and satisfaction. The manuscript management system is completely online and includes a very quick and fair peer-review system, which is all easy to use. Visit http://www.dovepress.com/testimonials.php to read real quotes from published authors. 